\section{Democracia participativa e processo decisório de políticas públicas: a influência da campanha contra a Alca}

Suylan de Almeida Midlej e Silva ${ }^{1}$

Resumo: Este artigo analisa a influência da Campanha Nacional contra a Área de Livre Comércio das Américas (ALCA), realizada de 2002 a 2006, no processo decisório do acordo da Alca. Discute-se a relação entre democracia participativa e movimentos sociais contemporâneos, a exemplo do Movimento por uma Nova Globalização, e reflete-se sobre participação social nas políticas públicas. Os resultados apontam que as ações da Campanha não influenciaram diretamente no desfecho do acordo, mas demonstram que houve intensa participação social nas instâncias decisórias de negociação da Alca, experiência antes inexistente no tocante à política externa brasileira. Para esta pesquisa, foram realizadas 17 entrevistas semiestruturadas e sete grupos focais, com 44 participantes, perfazendo um total de 61 entrevistados.

Palavras-chave: Democracia Participativa, Movimentos Sociais, Políticas Públicas, Alca.
Recebido:

22.06.11

Aprovado:

28.09.12

1. Doutora em Sociologia, professora adjunta do Departamento de Administração, do curso Gestão de Políticas Públicas e do mestrado profissional em Administração da Universidade de Brasília (UnB). Email: suylan@unb. br

\begin{abstract}
This article analyzes the influence of the Brazilian National Campaign against the Free Trade Area of the Americas (FTAA), which took place from 2002 to 2006, in the FTAA agreement decision-making process. It discusses the relation between participative democracy and contemporary social movements, such as the Movement for a New Globalization, and reflects upon social participation within public policies. The results point out that the campaign actions have not directly influenced the agreement closure, but show that there was intense social participation in the decision-making instances of the FTAA negotiations, an experience that was inexistent before in what concerns the Brazilian foreign policy. For this research, we carried out 17 semi-structured interviews, and counted on 7 focal groups, with 44 participants, totaling 61 interviewees.
\end{abstract}

Keywords: Participative Democracy, Social Movements, Public Policies, FTAA.

\title{
Introdução
}

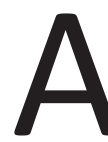

s relações entre sociedade e Estado têm se configurado de diversas formas, tanto a partir de ações não institucionalizadas, utilizando o "espaço da rua", mas com o objetivo claro de impactar a esfera estatal, quanto por meio da ocupação de espaços institucionalizados, usufruindo dos diversos 
2. A Campanha foi lançada em 2002 como Campanha Nacional contra a Alca, substituindo o nome, em 2004, para Campanha Brasileira contra a Alca, em função das campanhas nos outros países da América Latina e Caribe também terem sido nacionais. No presente artigo, será utilizada a nomenclatura Campanha Nacional contra a Alca.

3. O presente artigo baseia-se na minha tese de doutorado, defendida no Departamento de Sociologia da Universidade de Brasília (UnB), em agosto de 2008, com o título "Ganhamos a batalha, mas não a guerra": a visão da Campanha Nacional contra a Alca sobre a não assinatura do acordo. mecanismos de participação social, com a intenção de interferir nos processos decisórios de políticas públicas.

O cenário democrático tem se reinventado constantemente, dada a variedade de atores sociais e as diversas bandeiras, mas também as demandas específicas e as novas formas de interação entre sociedade civil e administração pública. Por isso, a renovação da teoria democrática requer a formulação de critérios democráticos de participação política, que não sejam confinados no ato de votar. Isso implicaria numa articulação entre democracia representativa e democracia participativa; o campo político teria que ser radicalmente redefinido e ampliado (SANTOS, 2005).

Essa necessidade de redefinição do campo político dá-se muito em função do direito de participação, mas não só deste, mas, sim, das recorrentes tentativas porparte dos movimentos sociais de exercer esse direito. Isso tem levado à criação de novas formas de atuação da administração pública, que alteram a sua relação com os administrados, com seus agentes e com sua estrutura hierárquica.

A Campanha Nacional contra a Área de Livre Comércio das Américas (CNA ${ }^{2}$ despontou no início desse milênio no Brasil como um movimento social articulado em rede com o Movimento por uma Nova Globalização (MNG), disposto a exercer a democracia participativa com o objetivo de impedir que as negociações do acordo da Alca avançassem rumo à sua assinatura, prevista para 2005.

O MNG reúne grupos de diversas partes do mundo que repudiam a liberalização do comércio, a ingerência das multinacionais nas economias locais e a degeneração dos direitos sociais adquiridos em processos de lutas coletivas desde as revoluções industriais. Também criticam a pouca transparência nos processos de negociação, que contam, em geral, com diplomatas e tecnocratas, e reivindicam a participação dos cidadãos nos destinos dos seus países. Por essa razão, a CNA identificou-se com esse movimento global.

A CNA foi criada em 2002 e realizou uma série de mobilizações, que resultou no Plebiscito Popular sobre a Alca, em 2002, obtendo mais de dez milhões de votos contrários ao acordo. Além dessa ação direta, também ocupou espaços institucionalizados, como a Frente Parlamentar de Acompanhamento à Alca, a Seção Nacional de Coordenação dos Assuntos Relativos à Alca (Senalca) e as Reuniões Ministeriais realizadas no Continente. Permaneceu ativa até 2006, quando os participantes encerraram suas atividades em função da suspensão das negociações.

Este artigo ${ }^{3}$ tem como objetivo analisar a influência da CNA no processo decisório do acordo da Alca, a partir da visão dos participantes da Campanha sobre o desfecho das negociações. Para isso, será realizada uma reflexão teórica sobre democracia participativa e movimentos sociais, abordando desde as formas de 
participação para além da esfera estatal como as constituídas dentro dos marcos da institucionalidade. Também se discutirá a participação e o processo decisório de políticas públicas, apontando os diversos aspectos da constitucionalização da democracia participativa.

Este estudo foi realizado no contexto de uma pesquisa qualitativa, a partir da utilização de análise documental, observação participante, entrevistas semiestruturadas e grupos focais. Como a Campanha produziu muitos documentos e material de divulgação, estes foram bastante analisados, mas também a documentação do Ministério das Relações Exteriores e da Câmara dos Deputados. Durante toda a pesquisa, foi possível acompanhar reuniões nacionais da Campanha, encontros de formação e preparação do plebiscito popular, como manifestações de rua. Foram realizadas 16 entrevistas individuais semiestruturadas com representantes da coordenação da Campanha Nacional contra a Alca, sete grupos focais com 44 participantes dos comitês estaduais da Campanha de sete estados brasileiros e com um representante do Ministério de Relações Exteriores (MRE), perfazendo um total de 61 entrevistados.

O critério para a seleção dos representantes da coordenação foi o grau de participação e de influência destes na própria Campanha. Os movimentos e as organizações foram selecionados conforme a participação do sujeito social/organização. Foram selecionados representantes dos seguintes movimentos: religioso (Pastorais Sociais, Grito dos Excluídos e organismos da Conferência Nacional dos Bispos do Brasil - CNBB: Cáritas Brasileira, Comissão Pastoral da Terra - CPT, Comissão Indigenista Missionária - Cimi e Instituto Brasileiro de Desenvolvimento - Ibrades); social (Movimento dos Trabalhadores Rurais Sem Terra - MST); político (Movimento Consulta Popular e o Partido Socialista dos Trabalhadores Unificado - PSTU); e sindical (Central Única dos Trabalhadores - CUT, Sindicato dos Advogados de São Paulo - SASP, Sindicato dos Auditores Fiscais da Receita Federal - Unafisco). Além da Rede Brasileira pela Integração dos Povos (Rebrip), a Aliança Social Continental (ASC), o Centro de Educação Popular do Instituto Sedes Sapientiae (Cepis) e uma representante da Secretaria Executiva da Campanha Nacional contra a Alca.

Foi utilizada a técnica de grupo focal (GF) para a realização de debate com alguns comitês estaduais em sete unidades da Federação: Bahia, Distrito Federal, Espírito Santo, Maranhão, Pará, Paraná e Rondônia. Essa técnica de investigação oferece informações qualitativas e revela experiências, sentimentos e percepções, além de otimizar tempo e recursos. Os grupos foram formados a partir de alguns critérios. Primeiro, pessoas que tivessem participado de um comitê estadual ou local da Campanha e que representassem uma das organizações ou movimentos componentes da Campanha. Outro critério para a seleção dos grupos foi também regional. Seria, então, realizado um GF pelo menos em cada 
região do País. Esse critério foi combinado com outro: o resultado da votação do plebiscito popular, tanto em valores absolutos quanto em número proporcional de eleitores, ou seja, em estados em que a votação tivesse sido expressiva ou não tão expressiva, para que se pudesse obter alguma comparação.

No caso do representante do MRE, o embaixador Antônio José Ferreira Simões foi chefe do Núcleo da Alca (Nalca) e da Coordenação Geral da Negociação da Alca (Coalca), secretário executivo da Senalca e coordenador geral da negociação da Alca, entre 1999 e 2002. Na negociação oficial da Alca, foi representante do MRE no Comitê de Representantes Governamentais para a Participação da Sociedade Civil.

As entrevistas e os grupos focais foram realizados entre outubro de 2006 e dezembro de 2007 e a análise de conteúdo do material foi efetivada a partir da organização de categorias por frequência das respostas.

Este artigo está estruturado em seis seções, incluindo esta introdução. A segunda seção discute a relação entre democracia participativa e movimentos sociais, caracterizando os movimentos sociais contemporâneos e as formas de participação; a terceira aborda a participação no processo decisório de políticas públicas, utilizando o marco constitucional e a relação entre sociedade civil e administração pública; a quarta descreve em linhas gerais como foi organizado o processo negociador da Alca e a criação da Campanha Nacional contra a Alca e suas principais ações; a quinta analisa os resultados da pesquisa a partir da visão da Campanha sobre o desfecho das negociações e suas diversas influências no processo decisório do acordo. Por fim, as considerações finais sintetizam os principais resultados encontrados.

\section{Democracia participativa e movimentos sociais}

Arendt (1994) afirma que o poder precisa do apoio e da organização popular para se manter. É do consentimento da opinião pública que vem a legitimidade do governo democrático. Na sua concepção, a democracia participativa pressupõe a coparticipação de cidadãos livres. Estes deixariam de ser governados por uma elite que deriva seu poder dos conselhos de assessorias intelectuais; o espaço de participação seria a própria esfera pública, compreendida como o espaço do bem comum, que interessa a todos os indivíduos, ainda que sob perspectivas diferentes (ARENDT, 2003).

Contemporaneamente, alguns autores apresentam uma nova formulação de democracia participativa, que assume a designação de democracia radical. Nesse caso, a política representaria o aprofundamento do projeto democrático da 
modernidade, em que é necessário um novo tipo de articulação entre o universal e o particular.

Segundo Mouffe (1996; 2005; 2006), a democracia radical propicia o resgate do político pelo estabelecimento de novas instituições para dar espaço ao pluralismo. Dessa forma, a democracia precisa ser exercitada para além da esfera estatal, pois a democratização das relações sociais deve ser baseada nos princípios da igualdade e da liberdade, o que mostra que a luta pela democracia no espaço estatal é insuficiente. Portanto, novas formas de participação política devem ser implantadas, levando em conta as amplitudes e especificidades das lutas democráticas atuais.

É preciso radicalizar a ideia de pluralismo, de forma a transformá-lo em um meio de aprofundamento da revolução democrática, sendo necessá-rio romper com o racionalismo, o individualismo e o universalismo. "Só nessa condição será possível apreender a multiplicidade de formas de sujeição que existem nas relações sociais e facultar um enquadramento para a articulação das diferentes lutas democráticas" (MOUFFE, 1996, p. 18).

Isso não significa rejeitar qualquer ideia de racionalidade, individualidade ou universalidade, mas essas lutas são necessariamente plurais, racionalmente construídas e comprometidas com relações de poder. Para a autora, na sua concepção de democracia radical e plural, é preciso reconhecer a existência permanente do conflito e do antagonismo; afinal, a existência de multiplicidade, de pluralidade e de conflito é a própria razão de ser da política.

Ainda para Mouffe, a restauração do valor da participação política é o que vai garantir o ressurgimento da esfera pública. Daí a necessidade de uma nova cultura política, em que haja uma nova concepção de cidadania e, assim, a construção de uma hegemonia democrática radical. Porém, a autora analisa que um projeto de democracia plural e radical reconhece a impossibilidade de uma completa realização da democracia e a conquista final da comunidade política: “o seu objetivo é utilizar os recursos simbólicos da tradição democrático-liberal para lutar pelo aprofundamento da revolução democrática, sabendo que se trata de um processo interminável" (MOUFFE, 1996, p. 99).

De acordo com Stanley Aronowitz (1992), esse projeto seria uma reivindicação resultante da análise empírica e histórica das práticas dos movimentos sociais, cujo veículo de intervenção tem sido as lutas sociais. O autor afirma que a democracia radical como posição política deve ser "um a priori ético" para não ser confundida com uma manifestação do desdobramento da história das lutas de classe ou das lutas pela formação de classes. A democracia radical não acarreta necessariamente desterritorialização, mas a construção de decisões a partir de 
baixo. "Baixo", para ele, inclui comunidades geograficamente definidas, como fábricas, escritórios e bairros, ou comunidades não agrupadas por um critério. O espaço desta política poderia situar-se nas comunidades intencionais ensaiadas por várias contraculturas.

O termo "radical" implica uma concepção de democracia que ultrapassa as formas parlamentares, ainda que inclua também a noção de governo representativo. Para Aronowitz, o socialismo, por exemplo, deve ser entendido como uma extensão da revolução democrática. E para os democratas radicais, a propriedade social, o Estado e o sistema legislativo já não são vistos como formas transitórias para uma ordem superior especificada pela história, mas, sim, como elementos importantes de uma formação social plural, na qual os movimentos sociais têm papel crucial e independente.

Da mesma forma, Mouffe e Laclau (2004) afirmam que a democracia radical supõe uma dimensão socialista, mas o socialismo é um dos componentes dessa democracia, e não o contrário. Neste caso, é necessário abandonar a ideia do socialismo entendido como um sistema social que exige o abandono dos princípios políticos do regime democrático-liberal. Mas, para os autores, não se pode abandonar os objetivos do socialismo, e estes devem ser concebidos como uma das dimensões da luta pelo aprofundamento da democracia.

Para Santos (2003; 2005), a renovação da teoria democrática requer a formulação de critérios democráticos de participação política que não confinem esta ao ato de votar. Implicaria uma articulação entre democracia representativa e democracia participativa. Para isso, o campo político deve ser "radicalmente" redefinido e ampliado.

A nova teoria democrática deverá proceder à repolitização global
da prática social e o campo político imenso que daí resultará permi-
tirá desocultar formas novas de opressão e de dominação, ao mes-
mo tempo em que criará novas oportunidades para o exercício de
novas formas de democracia e de cidadania. (SANTOS, 2003, p. 271)

Santos (2003) propõe reinventar a democracia por meio da construção de um novo contrato social, conflitual e inclusivo, uma vez que a nova democracia também exige uma repolitização do Estado, com outras concepções de bem comum. Para o autor, é preciso reinventar o espaço-tempo, em que seja favorecida a deliberação democrática. Um dos princípios defendidos por ele para que isso aconteça é a construção de um pensamento alternativo que permita o protagonismo das pessoas socialmente excluídas e, assim, uma democracia participativa.

A proposta teórica de Santos (2005) apoia-se em uma "exigência radical". Para 
ele, só haverá emancipação social na medida em que houver resistência a todas as formas de poder. Por isso, postula uma globalização alternativa, contra-hegemônica, organizada da base para o topo das sociedades. Ele cita as redes transnacionais de democracia participativa como um exemplo de modelo paralelo ao modelo hegemônico, em que grupos sociais que lutam contra as formas de exclusão estão interligados entre si em busca de formas de inclusão política.

É o caso, por exemplo, do Movimento por uma Nova Globalização (MNG), que reúne grupos de diversas partes do mundo para manifestar seu descontentamento com resistências e protestos contra a hegemonia do modelo neoliberal. Eles repudiam a liberalização do comércio, a ingerência das multinacionais nas economias locais e a degeneração dos direitos sociais adquiridos em

processos de lutas coletivas desde as revoluções industriais. Também criticam a pouca transparência nos processos de negociação, que contam, em geral, com diplomatas e tecnocratas, e reivindicam a participação dos cidadãos nos destinos dos seus países.

Na América Latina, o MNG influenciou a criação da Campanha Continental contra a Alca e, no Brasil, a da Campanha Nacional contra a Alca (CNA), que iniciou um movimento em 2002, a fim de impedir que as negociações do acordo avançassem rumo à sua assinatura, prevista para 2005. A CNA foi coordenada pela Campanha Jubileu Sul - rede ampla e plural de movimentos sociais, organizações populares e religiosas da América Latina e Caribe, África e Ásia que nasce no bojo das Campanhas do Jubileu 2000, coordenadas pelo Vaticano para o cancelamento das dívidas em todo o mundo.

Essa forma de organização em rede é uma forte característica dos movimentos sociais contemporâneos. Scherrer-Warren (2002, p. 248) conceitua o movimento social como "um conjunto de referências simbólicas, num campo de valores e práticas sociais, que vai sendo construído na memória e na ação coletiva, penetrando em vários níveis, nas relações familiares, comunitárias e societárias, no local, no nacional e no planetário". Para ela, a ideia de movimento social como categoria analítica deve ser distinguida das várias práticas concretas denominadas de "movimentos sociais" ou "movimentos populares". E a construção da categoria "deve ser buscada nos processos que transcendem os sujeitos coletivos em suas práticas particulares" (2002, p. 248).

É preciso passar da análise das organizações sociais específicas, fragmentadas, para a compreensão do movimento real que ocorre na articulação destas organizações nas redes de movimentos (SHERRER-WARREN, 1993). Também é necessário entender as interconexões de sentido entre o local e o global. Trata-se de uma nova cultura política que tem levado os movimentos locais a alargarem 
a sua visão e a unificarem as suas forças em frentes comuns de ação. Essa nova cultura política permite confrontar uma pluralidade de orientações e atores políticos, o que aponta para o pluralismo democrático, elemento central para a democracia participativa e radical.

O movimento em rede não é caracterizado apenas em função das conexões provocadas pelas tecnologias de comunicação, mas de sua composição variada de entidades e movimentos. A Campanha Nacional contra a Alca, por exemplo, foi composta por uma rede de organizações, movimentos sociais, políticos, religiosos e sindicais, bem como partidos políticos, e fez parte da Campanha Jubileu Sul, uma das redes que integra o MNG. Trata-se, portanto, de uma "rede de movimentos sociais", como define Sherrer-Warren (2006). No conceito da autora, "rede de movimento social pressupõe a identificação de sujeitos coletivos em torno de valores, objetivos ou projetos comuns, os quais definem os atores ou situações sistêmicas antagônicas que devem ser combatidas e transformadas" (SHERRER-WARREN, 2006, p. 113). As redes só se constituem em movimento social à medida que são reativas às contradições sistêmicas e buscam superar esses limites (SHERRER-WARREN, 2002). É nesse sentido que a rede pode assumir um caráter propositivo, tendo em vista seu efeito multiplicador e difusor de novos valores e de empoderamento dos movimentos. Nessa ótica, a rede pode desempenhar um papel estratégico, organizando, articulando e fortalecendo o movimento na sociedade civil e na relação com e contra outros poderes instituídos.

A sociedade civil organizada do novo milênio tende a ser uma sociedade de redes organizacionais, de redes inter-organizacionais e de redes de movimentos e de formação de parcerias entre as esferas públicas, privadas e estatais, criando novos espaços de governança com o crescimento da participação cidadã (SHERRER-WARREN, 2006). As redes de movimentos sociais possibilitam, nesse contexto, a transposição de fronteiras territoriais, temporais e sociais. Essas últimas compreendem o pluralismo de concepções de mundo dentro de determinados limites éticos, o respeito às diferenças e a radicalização da democracia, por meio do aprofundamento da autonomia relativa da sociedade civil organizada.

Segundo Gohn (2003), a participação cidadã funda-se também numa concepção democrática radical, cujo objetivo é fortalecer a sociedade civil para construir ou apontar caminhos para uma nova realidade social, sem desigualdades ou exclusões. Nesse caso, "a participação passa a ser concebida como uma intervenção social periódica e planejada, ao longo de todo circuito de formulação e implementação de uma política pública" (GOHN, 2003, p. 19).

Por essa razão, a autora argumenta que os movimentos passaram a atuar em rede e em parceria com outros atores sociais "dentro dos marcos da institucio- 
nalidade existente e não mais à margem, de costas para o Estado (...). A nova fase gerou práticas novas, exigiu a qualificação dos militantes. ONGs e movimentos redefiniram seus laços e relações" (GOHN, 2003, p. 30).

Esse novo ator sociopolítico tem como uma de suas bandeiras a participação democrática nas decisões que dizem respeito a todos os cidadãos e cidadãs. Essa demanda, no que se refere ao MNG, surgiu principalmente diante da falta de transparência nos mecanismos decisórios, como afirma Della Porta (2007, p. 75), particularmente "sigilosos" no caso da Organização Mundial do Comércio (OMC) e do Fundo Monetário Internacional (FMI), "que não apenas não oferecem canais de acesso a organizações da sociedade civil, mas mantêm em segredo as suas decisões políticas". A denúncia de um "deficit democrático" das estruturas supranacionais de governo não se conjuga, porém, com uma solicitação de mero fortalecimento da soberania dos Estados nacionais (DELLA PORTA, 2007). O que se propõe é a concepção de uma política diferente, baseada em um amplo envolvimento dos cidadãos, não só durante os períodos eleitorais, mas nos processos decisórios das políticas: uma democracia efetivamente participativa.

\section{Participação e processo decisório de políticas públicas}

A democracia participativa consiste em ampliar o controle da sociedade civil sob a administração pública, reservando aos cidadãos participação nas discussões sobre assuntos importantes para a coletividade. No Brasil, com a Constituição Federal de 1988, a participação está contemplada em todas as funções estatais: no Legislativo, no que se refere ao referendo, ao plebiscito e à iniciativa popular de leis; na garantia da fiscalização do Executivo por parte dos cidadãos; e no Judiciário, com instrumentos participativos como ações populares, mandados de segurança coletivos, entre outros (PEREZ, 2009).

Também em casos de reforma constitucional, ratificação de tratados ou convenções internacionais, empréstimos externos, modificações territoriais, declaração de guerra ou tratado de paz ou leis de máximo interesse nacional é a população quem decide em última instância. A Alca caracterizar-se-ia como um tratado continental, o que demandaria ampla discussão com a sociedade e aprovação do Congresso Nacional.

Conforme Teixeira (2007, p. 155), “a Constituição instaura elementos democráticos na gestão das políticas públicas, que sugerem um novo desenho das políticas sociais no Brasil, fundamentados nos princípios da descentralização, municipalização e participação da sociedade civil em todo o processo". Também estabelece que as políticas sociais sejam desenvolvidas com participação da sociedade, via órgãos representativos, nos espaços de deliberações das diretrizes 
das políticas, do planejamento, da execução, do controle e da supervisão dos planos, programas e projetos.

Para Perez (2004, p. 36), "o desenvolvimento democrático, refletido na constitucionalização da democracia participativa, é uma das razões fundantes da institucionalização da participação popular nas decisões e no controle da Administração Pública". Dessa forma, são garantidos aos cidadãos direitos específicos de participação, levando à criação de novas formas de atuação da administração pública, que alteram a sua relação com os administrados, com seus agentes e com sua estrutura hierárquica.A eficiência da atuação administrativa estaria relacionada à adesão da sociedade e à sua atuação ativa. "Daí a necessidade de se utilizar instrumentos que procurem o consentimento da coletividade, que procurem, enfim, a aproximação da sociedade e do Estado, do burocrata e do cidadão, do governante e do governado" (PEREZ, 2004, p. 221). A legitimidade viria em função dessa adesão da sociedade "a um conjunto de medidas concretas, políticas, ou programas que esta ajudou a formular, decidir e muitas vezes a executar" (PEREZ, 2004, p. 221). Essa legitimidade seria essencial para o êxito de políticas públicas.

Enquanto Max Weber compreende que o funcionamento da administração pública está centrado no trinômio burocracia, eficiência e legitimidade, Perez (2004) baseia-se no trinômio participação, eficiência e legitimidade. A participação seria uma forma de romper com o distanciamento entre a sociedade e a administração, aproximando essa administração dos conflitos sociais e políticos e delegando responsabilidade também aos entes da sociedade, ao contrário do modelo burocrático, que defende a autonomia da administração em relação à sociedade, delegando apenas aos administradores a gestão técnica e profissional dos serviços públicos.

Para o autor, a participação da sociedade na Administração Pública implica na organização de processos de tomada de decisão por essa modalidade de administração ou de divisão de tarefas entre a administração e os administrados, em que estes últimos poderiam ser convocados à execução direta de determinadas funções administrativas.

Desse modo, existiriam variados institutos de participação popular que levam à participação da sociedade na decisão, formulação e implementação de políticas públicas. Exemplos de participação nos processos decisórios de políticas públicas são o plebiscito administrativo, o referendo e as comissões de caráter deliberativo; de formulação seriam as audiências e consultas públicas; e de implementação, as comissões de usuários, a atuação de organizações sociais ou de entidades de utilidade pública (PEREZ, 2004, p. 224-225). 
O plebiscito administrativo "pode ser definido como o procedimento de consulta popular aberto a todos os cidadãos, prévio a tomada de uma decisão administrativa, que vincula a Administração ao cumprimento de seu resultado" (PEREZ, 2004, p. 154). Essa modalidade de plebiscito era aquela que a CNA reivindicava que a administração pública brasileira realizasse como forma de consulta sobre a assinatura do acordo da Alca. Havia uma expectativa da Campanha, com isso, de que, se houvesse um plebiscito oficial, o resultado seria contrário à Alca e de que essa seria uma forma efetiva de influenciar a política externa.

As normas jurídicas e o respeito aos direitos são o fundamento básico da convivência social das democracias "evoluídas", mas o fenômeno estatal tem que ser visto além da perspectiva jurídica (SARAVIA, 2006). É preciso "analisar o funcionamento do Estado por meio de seus fluxos, da sua dinâmica, e modificar, assim, a perspectiva - até então privilegiada ou única - de exame de normas e estruturas" (SARAVIA, 2006, p. 26). Segundo Saravia, trata-se de visões complementares. A perspectiva da política pública integra a dimensão jurídica e esta vale-se dos insumos produzidos pelas análises de política pública.

No caso da América Latina, a teoria da administração pública ficou presa entre as considerações jurídico-institucionais e as considerações administrativas sobre cumprimento de ordens e execução de decisões prévias (VILLANUEVA apud SARAVIA, 2006). "Ao aproximar a administração pública do processo decisório das políticas e da sua complexa colocação em prática, seria possível resgatar seu esquecido sentido clássico de governo, de bom governo, e poder-se-ia reconstruir a visão integral de seu objeto de estudo" (VILLANUEVA apud SARAVIA, 2006, p. 27).

Um conceito de cunho jurídico define política pública como um programa de ação governamental resultante de um processo ou conjunto de processos juridicamente regulados, "visando coordenar os meios à disposição do Estado e as atividades privadas, para objetivos socialmente relevantes e politicamente determinados" (BUCCl, 2006, p. 39). Para Saravia (2006, p.29), política pública é um sistema de decisões públicas destinadas "a manter ou modificar a realidade de um ou vários setores da vida social, por meio da definição de objetivos e estratégias de atuação e da alocação dos recursos necessários para atingir os objetivos estabelecidos".

Há uma aparente não governabilidade das políticas públicas e da ação governamental, afetando não só o cidadão, mas os atores administrativos, políticos e seus analistas, que ressaltam a complexidade das políticas públicas e as aparentes debilidades do Estado para cumpri-las (SARAVIA, 2006).

No caso da política pública aqui em questão, a política externa sobre a Alca, 
pode-se perceber uma complexidade de origem, dada a sua formulação ter sido realizada por integrantes de vários países do continente. Porém, outro aspecto a ser analisado, dessa vez no tocante à governabilidade, é o fato de, no Brasil, esta ter estado sob a execução do Ministério das Relações Exteriores, estrutura historicamente refratária à participação da sociedade. Isso dificultou a participação social no processo decisório, apesar de se ter observado certa abertura durante a etapa de finalização das negociações.

Em tese, a política externa deveria ser tratada como qualquer outra política pública, inclusive no tocante aos mecanismos de participação social. SegundoSanchez et al (2006), a Constituição Federal de 1988 (CF) disponibiliza possíveis formas de controle sobre o poder público para supervisão da política externa, como qualquer outra política pública, em cada uma de suas fases (formulação, decisão, implementação e avaliação), que devem ser conduzidas por meio de atos e normas da administração pública, em razão do princípio da legalidade e da publicidade.

Porém, a utilização deste tipo de controle sobre a política externa baseada nos princípios do artigo 37 da Constituição de 1988 (legalidade, impessoalidade, moralidade, publicidade e eficiência) é questão que fica em aberto, não sendo possível identificar formas explícitas de controle sobre a política externa. Por outro lado, o controle dos atos administrativos a partir de princípios pode ser um modelo para o controle da política externa, inclusive a partir dos princípios que regem as relações internacionais arrolados no artigo 4ㅇ da Constituição Federal (SANCHEZ, 2006).

\section{A Alca e a CNA}

A tentativa dos Estados Unidos de criar uma Área de Livre Comércio nas Américas remonta ao final do século XIX, quando da realização da I Conferência Pan-Americana, em 1889. Ao longo do século XX, aconteceram outras investidas, mas somente em 1994, com a Cúpula das Américas, em Miami, ela ganhou força, sendo proposto o Tratado para a criação da Área de Livre Comércio das Américas (Alca). Ao todo, fariam parte 34 países, exceto Cuba, que foi excluído das negociações sob o argumento de se tratar de um país não democrático.

O processo negociador da Alca aconteceu em três etapas: preparação das negociações (de 1994 a 1998), quando foram definidos princípios, objetivos gerais e prazos para a implementação da Alca; início das negociações (de 1998 a 2002); estágio em que foram redigidos os acordos e discutido cada um dos temas em negociação; e finalização das negociações (de 2002 a 2004), fase em que se deu a definição de direitos comuns para todos os países e a construção das ofertas, que significariam o passo anterior à assinatura do acordo, o que nunca ocorreu. 
As negociações foram estruturadas a partir de três instâncias. A principal foi constituída pelos representantes governamentais, que tinham a incumbência de estabelecer os objetivos e princípios gerais do projeto da Alca. Esse grupo de chefes de Estado e de governo reunia-se nas Cúpulas das Américas. Durante o processo negociador, foram realizadas quatro edições: Miami (1994), Santiago (1998), Quebéc (2001), Mar del Plata (2005), além de uma reunião extraordinária em Monterrey (2004).

A segunda instância de negociação foi formada pelos ministros de comércio, encarregados de elaborar as diretrizes e o plano de trabalho da Alca e de estabelecer as responsabilidades e as metas das outras instâncias de negociação. Essas deliberações ocorriam durante as Reuniões Ministeriais, realizadas em oito edições até o final das negociações. Dentro dessa instância, foi formado, a partir do começo das negociações, em 1998, o Comitê de Negociações Comerciais (CNC), integrado pelos vice-ministros de comércio, que eram responsáveis pela orientação permanente das negociações. O Comitê realizou 17 reuniões entre junho de 1998 e fevereiro de 2004.

A presidência das negociações foi rotativa e o país que sediava a Reunião Ministerial também presidia o Comitê de Negociações Comerciais. De 1으 de novembro de 2002 até o final das negociações, Brasil e Estados Unidos foram copresidentes do Comitê de Negociações Comerciais.

A Campanha Nacional contra a Alca (CNA) foi lançada exatamente no início de 2002, na fase de finalização das negociações, por um grupo de organizações brasileiras, constituindo-se em uma rede de movimentos sociais, em consonância com o Movimento por uma Nova Globalização. A principal estratégia de mobilização da sociedade empreendida por essa rede foi a realização de um plebiscito sobre a Alca. Esta seria também a tentativa inicial de participação no processo decisório da política externa por meio da pressão popular.

No Brasil, a Campanha foi coordenada por diversas organizações. Destacam-se a Conferência Nacional dos Bispos do Brasil (CNBB), com suas pastorais sociais e organismos; o Movimento dos Trabalhadores Rurais Sem Terra (MST); a Central Única dos Trabalhadores (CUT); o Partido Socialista dos Trabalhadores Unificados (PSTU); alguns segmentos do Partido dos Trabalhadores (PT); e a Organização Não Governamental Rede Brasileira pela Integração dos Povos (Rebrip). No total, a Campanha foi composta por cerca de 60 organizações nacionais.

O plebiscito, realizado durante a semana da Pátria, de 1 으 7 de setembro de 2002, foi um dos momentos mais significativos da CNA, ocorrendo também em outros países do continente. A votação final divulgada oficialmente pela Campanha chegou ao total de 10 milhões e 234 mil e 143 para 46 mil e 475 urnas 
apuradas, com a participação de 120 mil e 860 voluntários. O plebiscito abordou três questões, com os respectivos números de votantes, como se pode observar na Tabela 1.

A questão 3, sobre a base Militar de Alcântara, foi a que obteve maior percentual de resposta "Não" (98,59\%), e o menor de resposta Sim (0,65\%). Foi também o menor número de votos nulos e brancos, $0,21 \%$ e 0,01\%, respectivamente. Essa foi a pergunta mais direta no tocante à soberania nacional, apelo principalda Campanha.

Tabela 1: Resultado da apuração do Plebiscito Popular sobre a Alca

\begin{tabular}{|l|l|l|l|l|l|}
\hline \multicolumn{1}{|c|}{ Questão } & \multicolumn{1}{c|}{ Sim } & \multicolumn{1}{c|}{ Não } & Brancos & Nulos & \multicolumn{1}{c|}{ Total } \\
\hline $\begin{array}{l}\text { 1. O governo brasi- } \\
\text { leiro deve assinar o } \\
\text { tratado da Alca? }\end{array}$ & $\begin{array}{l}115.277 \\
(1,3 \%)\end{array}$ & $\begin{array}{l}10.062 .224 \\
(98,32 \%)\end{array}$ & $\begin{array}{l}32.768 \\
(0,32 \%)\end{array}$ & $\begin{array}{l}23.874 \\
(0,23 \%)\end{array}$ & $\begin{array}{l}10.234 .143 \\
(100 \%)\end{array}$ \\
\hline $\begin{array}{l}\text { 2. O governo brasi- } \\
\text { leiro deve continuar } \\
\text { participando das } \\
\text { negociações da Alca? }\end{array}$ & 344.037 & $\begin{array}{l}9.818 .108 \\
(3,36 \%)\end{array}$ & $\begin{array}{l}(95,93 \%) \\
(0,48 \%)\end{array}$ & $\begin{array}{l}22.986 \\
(0,22 \%)\end{array}$ & $\begin{array}{l}10.234 .143 \\
(100 \%)\end{array}$ \\
\hline $\begin{array}{l}\text { 3. O governo brasilei- } \\
\text { ro deve entregar parte } \\
\text { de nosso território - a } \\
\begin{array}{l}\text { Base de Alcântara - } \\
\text { para controle militar } \\
\text { dos Estados Unidos? }\end{array}\end{array}$ & $\begin{array}{l}66.869 \\
(0,65 \%)\end{array}$ & $\begin{array}{l}10.090 .192 \\
(98,59 \%)\end{array}$ & $\begin{array}{l}1.100 \\
(0,01 \%)\end{array}$ & $\begin{array}{l}21.630 \\
(0,21 \%)\end{array}$ & $\begin{array}{l}10.234 .143 \\
(100 \%)\end{array}$ \\
\hline
\end{tabular}

Fonte: Elaboração da autora a partir do Manifesto da Campanha Nacional contra a Alca, set. 2002

A questão 1 , sobre a assinatura do tratado, foi a segunda a obter mais votos contrários, 98,32\%; e 1,13\% de votos favoráveis, tendo o maior percentual de votos nulos, $0,23 \%$, e o segundo em votos brancos, $0,32 \%$. Essa questão foi a mais direta sobre a aceitação ou não da Alca; também teve uma grande votação, apenas com uma diferença ínfima de 0,27\% em relação à questão 3.

A questão 2, sobre a participação do Brasil nas negociações, foi a que teve menos votos contrários, 95,93\%, e mais votos favoráveis, 3,36\%, com o maior índice de votos brancos, $0,48 \%$, e o segundo de votos nulos, 0,22\%. Essa questão, segundo depoimentos de integrantes da Campanha, foi a mais polêmica. As pessoas queriam saber se o Brasil poderia continuar participando das negociações sem comprometer a sua autonomia. 
O plebiscito popular foi uma etapa importante, mas a Campanha não se encerrou com a sua votação. Os integrantes passaram a participar dos espaços institucionalizados, primeiro na Frente Parlamentar de Acompanhamento à Alca, no Congresso Nacional; em seguida, na delegação brasileira durante as Reuniões Ministeriais das negociações da Alca, realizadas em diversos países do continente americano; e nas reuniões da Seção Nacional de Coordenação dos Assuntos Relativos à Alca (Senalca), sob a coordenação do Ministério das Relações Exteriores (MRE), órgão responsável pela preparação das posições brasileiras para as negociações da Alca, criado em outubro de 1996 pela Presidência da República.

Em novembro de 2003, na VIII Reunião Ministerial de Miami, o governo brasileiro não aceitou avançar no processo negociador, tendo como referência a Alcaabrangente concebida inicialmente pelos Estados Unidos, e apresentou novo formato para a condução das negociações, conhecido como "Alca Light". Foi, então, incorporado o conceito de flexibilidade no processo negociador hemisférico. Esse conceito, contido no parágrafo 7 da Declaração de Miami, reconhece que os países no âmbito da Alca podem assumir diferentes níveis de compromissos, conduzindo negociações bilaterais ou plurilaterais.

Essa foi a última Reunião Ministerial. Depois dessa, aconteceram mais duas reuniões da Cúpula das Américas, em 2004 e 2005, e as negociações foram suspensas. Depois de dez anos de negociação, a Alca, prevista para ser assinada em janeiro de 2005, não foi adiante. Mesmo assim, a CNA ainda continuou com algumas ações, uma dessas foi a participação nas Assembléias Populares, que realizavam discussões sobre um projeto popular para o Brasil e alternativas à Alca, culminando na entrega de uma carta de reivindicações ao governo brasileiro.

Em 2006, a Campanha encerrou suas atividades, mas o tema Alca continuou sendo acompanhado por outras organizações, como a Aliança Social Continental e a Rebrip. A partir de então, a ênfase seria dada ao tema da integração regional em consonância com a Campanha Continental e com as ações do Movimento por uma Nova Globalização.

\section{Visão da CNA sobre o desfecho das negociações}

A Campanha Nacional contra a Alca valeu-se do princípio constitucional de que um acordo do porte da Alca deveria ser aprovado pelo Congresso Nacional antes de ser assinado e estruturou sua estratégia de participação no processo decisório dessa política externa de duas formas: o agir coletivo não institucionalizado, por meio prioritariamente da realização do plebiscito popular; e ações político-institucionais, por meio da participação em espaços já institucionalizados, a exemplo da Senalca e das Reuniões Ministeriais de negociações da Alca. 
Pode-se afirmar que houve forte participação da Campanha, tanto nos espaços não institucionalizados como nos institucionalizados, o que em si já é algo novo em se tratando das políticas externas brasileiras. Porém, nem no primeiro caso, nem no segundo, a Campanha conseguiu o resultado esperado: a retirada do Brasil das negociações da Alca. Ao contrário, o governo cumpriu todas as etapas das negociações, o que frustrou a maioria dos militantes da CNA.

Na visão da Campanha, conforme foi possível acompanhar pelos depoimentos dos militantes e dos outros entrevistados durante a pesquisa, a não assinatura do acordo da Alca foi atribuída a três causas principais: a influência da política externa brasileira, a influência de outros governos latinoamericanos e o desinte-resse do governo dos Estados Unidos.

Na visão da grande maioria dos entrevistados, a visão que desponta em primeiro lugar é a influência da política externa brasileira. A partir dessa tese, surgiu outra indagação. O que teria influenciado o processo decisório da política externa brasileira? E aqui apareceram mais três causas: a Campanha Nacional contra a Alca; o governo brasileiro e os gestores da política externa; e os interesses do agronegócio brasileiro.

Para a maior parte dos entrevistados, as duas primeiras causas teriam influenciado o processo decisório da política externa brasileira: a mobilização social provocada pela realização do plebiscito popular, combinada com a eleição do presidente Lula da Silva. De modo geral, os entrevistados analisam que a opinião pública construída pelo movimento social foi utilizada na mesa de negociação sobre a Alca, ora para dirimir conflitos internos do governo, ora para fortalecer o posicionamento brasileiro nas negociações hemisféricas.

O resultado do plebiscito com os dez milhões de votos, para alguns entrevistados, foi também uma forma de resistir às pressões dos Estados Unidos, pois até 2002 as negociações vinham seguindo um curso dentro de certa normalidade. Após o plebiscito, que acontecera em setembro desse mesmo ano, o cenário mudou, provocando "um desequilíbrio nas negociações". Aqui, é preciso analisar alguns aspectos. Primeiro, era possível deduzir que as negociações mudassem o rumo, afinal aquele era o período de preparação das ofertas nos nove grupos negociadores, etapa fundamental para a finalização do processo negociador. Depois, houve mudança de governo com a eleição, que também deu outro tom às negociações.

Também o fato de a política externa passar a ser conduzida pelo ministro Celso Amorim e pelo secretário-geral Samuel Pinheiro Guimarães, na visão dos entrevistados, teve um efeito prático, que auxiliou na condução da política externa em uma perspectiva nacionalista e desenvolvimentista: voltada para a defesa de 
uma política governamental de promoção do desenvolvimento econômico, com ênfase na industrialização do País, linha adotada à época pelo Ministério das Relações Exteriores (MRE) no caso das negociações da Alca.

Essa visão de que a política externa brasileira deu o tom nas negociações é ainda mais fortalecida em razão de Samuel Pinheiro Guimarães ter assumido publicamente um posicionamento contrário à Alca antes mesmo de assumir o cargo no novo governo, além de ter sido um dos mentores intelectuais da CNA. Para muitos entrevistados, a própria composição do MRE no início do governo Lula da Silva expressa esse posicionamento. Por isso, parece não ter sido necessariamente a realização do plebiscito ou a Campanha em si que influenciaram a

política externa do governo brasileiro, já que não havia vontade política do governo para a assinatura do acordo.

Mas, para alguns entrevistados, é preciso notar que essa falta de vontade política pode ter ocorrido em função dos interesses do agronegócio brasileiro, o que representaria uma maior influência da força do mercado. Quantitativamente, essa opinião não foi significativa, haja vista que dentro do universo pesquisado poucos entrevistados opinaram nessa direção, mas há que se considerar a consistência dos argumentos aliada ao perfil desses analistas. O conteúdo da argumentação vai ao encontro de algumas declarações dos representantes da política externa brasileira, incluindo o Presidente da República, Lula da Silva (SILVA, 2005), que ponderou em seu discurso na IV Cúpula das Américas, em Mar del Plata, que "não faz sentido falar em livre comércio enquanto persistem os gigantescos subsídios da agricultura que desnivelam o campo de jogo".

Como argumentam alguns dos entrevistados, a preocupação com os subsídios agrícolas significava a preocupação com o mercado. Para eles, se fosse resolvido o problema do subsídio agrícola, talvez o acordo tivesse sido assinado, mas não houve consenso em torno desse tema; o agronegócio percebeu que não lucraria com as condições oferecidas naquele estágio do acordo. A argumentação nesse sentido foi feita pelos representantes da Campanha que participavam mais diretamente das mesas de negociação, em âmbito interno e externo. Também alguns militantes dos comitês estaduais emitiram a mesma opinião.

Mesmo considerando que a maioria dos entrevistados acredita que o governo brasileiro, por meio de sua política externa, foi quem mais contribuiu para o desfecho das negociações, alguns percebem que outros governos latinoamericanos também influenciaram na não assinatura do acordo. Isso teria ocorrido em função da crise do projeto neoliberal e o consequente sentimento anti-imperialista que se difundiu na América Latina, provocando uma alteração considerável no processo eleitoral de alguns países entre os anos 2002 e 2006, dentre eles Brasil, Argentina, Venezuela, Bolívia, Uruguai e Equador, cuja principal bandeira empu- 
nhada pelos candidatos eleitos foi o combate ao neoliberalismo. Nesse caso, para esses entrevistados, também houve uma grande influência tanto da Campanha Nacional contra a Alca, como da Campanha Continental.

A outra razão apresentada pelos entrevistados como causa da não assinatura foi a mudança de foco dos Estados Unidos em relação à Alca. Segundo alguns entrevistados, o interesse do país mudou quando foi deflagrada a Guerra do Iraque. Mas para outros militantes, foi a intransigência estadunidense em relação à suspensão dos subsídios agrícolas que levou ao recuo nas negociações.

Em se tratando da influência da CNA, para a grande maioria dos entrevistados, o plebiscito popular teve um papel muito mais importante do que a participação nos espaços institucionalizados, como na Senalca e nas Reuniões Ministeriais das negociações da Alca. Mesmo assim, na visão dos entrevistados, os dez milhões de votos do plebiscito foram utilizados de acordo com o interesse do governo, como um objeto de barganha na mesa de negociação. No caso das instâncias oficiais, embora os integrantes da Campanha tivessem conseguido conquistar esses espaços, na perspectiva da administração pública, foi possível perceber a manutenção do modelo burocrático, que impõe a autonomia da administração em relação à sociedade, enfatizando uma gestão técnica e profissional dos serviços públicos apenas pelos administradores (PEREZ, 2004), pois a demanda pela realização de um plebiscito oficial foi ignorada: os representantes da sociedade civil não tinham direito nem a voz nem a voto nas Reuniões Ministeriais, eram meros observadores. A Senalca tinha um caráter mais informativo sobre as negociações, não tendo, portanto, espaço para interferência nesse mesmo segmento.

Esse dado remete à questão de que os espaços de participação política são, muitas vezes, criados para legitimar um posicionamento prévio de um determinado grupo ou governante (MELUCCl, 1996). Contudo, a participação mesmo sem voz e voto também abre possibilidade para que determinado grupo defenda seus interesses e exerça influência sobre decisões dentro de um sistema político. Esse autor adverte que é preciso observar, nesse contexto, quais são as regras e limites dessa participação.

O Parlamento brasileiro foi outro espaço aproveitado pela CNA. Antes mesmo da realização do Plebiscito Popular, em 2002, alguns representantes da coordenação da Campanha pleitearam, junto a alguns parlamentares, a criação de uma Frente Parlamentar contra a Alca. Essa demanda acabou se realizando em junho de 2003, quando foi lançada a Frente Parlamentar de Acompanhamento das Negociações da Alca e em Defesa da Soberania. Porém, o próprio nome já não correspondia aos anseios da Campanha, que propunha uma Frente "contra a Alca" e não de acompanhamento das negociações. 
Diante disso, ao contrário do que aconteceu no tocante ao Poder Executivo, a Campanha interrompeu sua interlocução com o Poder Legislativo. Inicialmente, a CNA acreditou que a Frente pudesse, se não lograsse influenciar o posicionamento do governo brasileiro pela não assinatura do acordo da Alca, pelo menos viabilizaria a realização do plebiscito oficial, apostando que o resultado dessa consulta seria contrário à Alca, o que poderia resultar na retirada do Brasil das negociações. Como o andamento das atividades da Frente não sinalizava esse ganho, essa relação foi interrompida e, mais uma vez, a tentativa de emperrar o processo decisório foi frustrada. Ou seja, essa instância para a grande maioria dos entrevistados, nada influenciou o desfecho das negociações da Alca.

\section{Considerações finais}

A Campanha Nacional contra a Alca propôs-se a debater um tema árido e desconhecido para a população brasileira, usando como estratégia primeira a mobilização da sociedade civil. Para isso, um plebiscito foi organizado extraoficialmente, com a participação expressiva de quase $10 \%$ do eleitorado brasileiro. Sem dúvida, a Campanha preparou a militância; demais grupos conseguiram levar sua opinião para a esfera pública, influenciando mais de dez milhões de votantes, que participaram do plebiscito de forma espontânea e não obrigatória. Esse universo estava longe de representar a população brasileira, mas informava sobre a capacidade de ação coletiva de um movimento social que pretendeu influenciar o processo decisório do acordo da Alca.

Conforme colocaram os entrevistados, esse resultado foi utilizado pelo governo e pelos gestores do Ministério das Relações Exteriores na mesa de negociação durante as Reuniões Ministeriais da forma que eles achassem conveniente, mas efetivamente não gerou o resultado desejado: a realização de um plebiscito oficial, que poderia levar a um resultado contrário à Alca e, por conseguinte, à retirada do Brasil das negociações.

O agir coletivo não institucionalizado foi a principal estratégia da Campanha, sobretudo por envolver os comitês estaduais e municipais de todo o Brasil, uma experiência de mobilização social de grande porte, haja vista o resultado do plebiscito, não só pelo número de votantes, mas também pelos voluntários envolvidos, mais de 120 mil; além disso, pela mobilização articulada em uma rede nacional e mundial de movimentos sociais. Porém, não só essa ação foi responsável por tornar ativa a Campanha, ela persistiu praticamente por mais quatro anos, pressionando o governo brasileiro pela não assinatura do acordo, ocupando, desta vez, também os espaços institucionalizados.

É inegável que houve abertura das instâncias negociadoras do governo brasileiro 
para a participação da sociedade civil no processo negociador da Alca, mas esta apenas atuava como observadora. Isso levou a uma frustração em relação à expectativa da influência da Campanha nesses espaços institucionais de poder, tanto para quem estava diretamente na negociação quanto para os militantes dos estados e municípios. Contudo, os próprios entrevistados reconhecem o êxito da participação da sociedade civil em uma política pública governamental conduzida por uma estrutura de poder considerada hermética, o MRE, tendo esse ministério criado mecanismos de participação popular em suas estruturas internas a partir da pressão social, conforme o próprio embaixador entrevistado afirmou.

Nesse caso, a pressão social provocou a diminuição do distanciamento entrea sociedade e a administração, aproximando essa administração dos conflitos sociais e políticos e alterando a relação entre administrados, agentes públicos e estrutura interna. Ou seja, tratou-se de uma nova forma de atuação da administração pública. No entanto, não ocorreu, propriamente, a institucionalização da participação popular nos processos decisórios da política pública externa sobre a Alca.

É certo que falar de participação como direito conquistado e previsto constitucionalmente sem falar de efetividade não é muito animador do ponto de vista dos ganhos imediatos no jogo político. Mas desprezar a intensa participação social nas instâncias decisórias de negociação da Alca, ocorrida a partir da pressão de uma rede de movimentos sociais conhecida como Campanha Nacional contra a Alca, é deixar de reconhecer os avanços democráticos adquiridos. Portanto, importa aqui analisar a dimensão do exercício de democracia participativa e todo o aprendizado dessa experiência.

Referências bibliográficas

ARENDT, H. A condição humana. Rio de Janeiro: Forense Universitária, 2003. . Sobre a violência. Rio de Janeiro: Relume Dumará, 1994.

ARONOWITZ, S. "Pós-Modernismo e Política". In: HOLLANDA, H. B. (org). Pós-Modernismo e Política. Rio de Janeiro: Rocco, 1992.

BUCCI, M. P. D. (org.) Políticas Públicas: reflexões sobre o conceito jurídico. São Paulo: Saraiva, 2006.

CAMPANHA CONTINENTAL CONTRA A ALCA. "Declaração Final do I Encontro Hemisférico de Luta contra a Alca". In: Campanha Nacional contra a Alca (org.) Soberania Sim, Alca Não!. São Paulo: Expressão popular, 2002. 
GOHN, M. G. Movimentos Sociais no Início do Século XXI: antigos e novos atores sociais. Petrópolis, RJ: Vozes, 2003.

GOMES, G. "O Brasil frente ao desafio da Alca: contribuição ao debate". In: Comissão Brasileira Justiça e Paz. Brasília, 2004.

MELUCCI, A. Challenging codes: collective action in the information age. Cambridge: Cambridge University Press, 1996.

LACLAU, E.; MOUFFE, C. Hegemonía y estrategia socialista hacia una radicalización de la democracia. Argentina: Fondo de Cultura Económica de Argentina, 2004.

MOUFFE, C. On the political: thinking in action. Londres e Nova York: Routlegde, 2006.

(org.) Desconstrucción y pragmatismo. Buenos Ayres: Paidós, 2005.

. O regresso do político. Lisboa: Gradiva, 1996.

PEREZ, M. A. A Administração pública democrática: institutos de participação popular na Administração Pública. Belo Horizonte: Fórum, 2004.

PORTA, D. O movimento por uma nova globalização. São Paulo: Edições Loyola, 2007.

SANCHEZ, M. R. et al. "Política externa como política pública: uma análise pela regulamentação brasileira (1967-1988)". Revista Sociologia Política, Curitiba, nov. 2006, p. 125-143.

SANTOS, B. de S. Democratizar a democracia: os caminhos da democracia participativa. Rio de Janeiro: Civilização Brasileira, 2005.

. Pela Mão de Alice: o social e o político na pós-modernidade. São Paulo: Cortez, 2003.

SARAIVA, E. "Introdução à Teoria da Política Pública". In: SARAVIA e FERRAREZI (orgs.) Políticas Públicas: coletânea. Brasília: ENAP, 2006, vol. 1.

SILVA, L. I. Lula da (2005). In: Declaração Ministerial da IV Cúpula das Américas. Mar del Plata. Disponível em: www.alca-ftaa.org. Acesso em: 03 de set. 2006.

SCHERRER-WARREN, I. Redes de Movimentos Sociais. São Paulo: Edições Loyola, 1993.

- "Ações coletivas na sociedade contemporânea e o paradigma das redes". Sociedade e Estado, v. 13, no 1, 1998. 
. "Redes e sociedade civil global". In: HADDAD, S. (org.) ONGs e universidades. São Paulo: ABONG; Peirópolis, 2002.

. "Das mobilizações às redes de movimentos sociais". Sociedade e Estado, vol. 21, $\mathrm{n}^{\circ} 1,2006$.

TEIXEIRA, S. M. "Descentralização e participação social: o novo desenho das políticas sociais". Revista Katalysis, vol. 10, no 2, 2007, p. 154-163. 